\title{
Miningo
}

http://dx.doi.org/10.1590/0370-44672017710129

Felipe Ribeiro Souza

Doutorando

Universidade Federal de Minas Gerais - UFMG Escola de Engenharia

Departamento de Engenharia de Minas

Belo Horizonte - Minas Gerais - Brasil

felipecmc@globomail.com

\section{Hudson Rodrigues Burgarelli}

Mestrando

Universidade Federal de Minas Gerais - UFMG

Escola de Engenharia

Departamento de Engenharia de Minas

Belo Horizonte - Minas Gerais - Brasil

hburgarelli@gmail.com

\section{Alizeibek Saleimen Nader \\ Professor \\ Universidade Federal de Minas Gerais - UFMG \\ Escola de Engenharia \\ Departamento de Engenharia de Minas \\ Belo Horizonte - Minas Gerais - Brasil \\ beckn@demin.ufmg.br, beckn@usp.br}

\section{Carlos Enrique Arroyo Ortiz}

\section{Professor}

Universidade Federal de Minas Gerais - UFMG Escola de Engenharia

Departamento de Engenharia de Minas

Belo Horizonte - Minas Gerais - Brasil

carroyo@demin.ufmg.br

\section{Leonardo Soares Chaves}

Mestrando

Universidade Federal de Minas Gerais - UFMG

Escola de Engenharia

Departamento de Engenharia de Minas

Belo Horizonte - Minas Gerais - Brasil

leosoaresc@hotmail.com

\section{Luiz Alberto Carvalho}

Mestrando

Universidade Federal de Minas Gerais - UFMG

Escola de Engenharia

Departamento de Engenharia de Minas

Belo Horizonte - Minas Gerais - Brasil

luizalbertopersonal@gmail.com

\section{Vidal Félix Navarro Torres}

Pesquisador do Instituto Tecnológico da VALE -

Mineração e Geomecânica

Ouro Preto - Minas Gerais - Brasil

vidal.torres@itv.org,navarro.cvl@sapo.pt

\section{Direct block scheduling technology: Analysis of Avidity}

\section{Abstract}

This study is focused on Direct Block Scheduling testing (Direct Multi-Period Scheduling methodology) which schedules mine production considering the correct discount factor of each mining block, resulting in the final pit. Each block is analyzed individually in order to define the best target period. This methodology presents an improvement of the classical methodology derived from Lerchs-Grossmann's initial proposition improved by Whittle. This paper presents the differences between these methodologies, specially focused on the algorithms' avidity. Avidity is classically defined by the voracious search algorithms, whereupon some of the most famous greedy algorithms are Branch and Bound, Brutal Force and Randomized. Strategies based on heuristics can accentuate the voracity of the optimizer system. The applied algorithm use simulated annealing combined with Tabu Search. The most avid algorithm can select the most profitable blocks in early periods, leading to higher present value in the first periods of mine operation. The application of discount factors to blocks on the Lerchs-Grossmann's final pit has an accentuated effect with time, and this effect may make blocks scheduled for the end of the mine life unfeasible, representing a trend to a decrease in reported reserves.

Keywords: mine planning, scheduling, avidity optimization, simulated annealing, tabu search. 


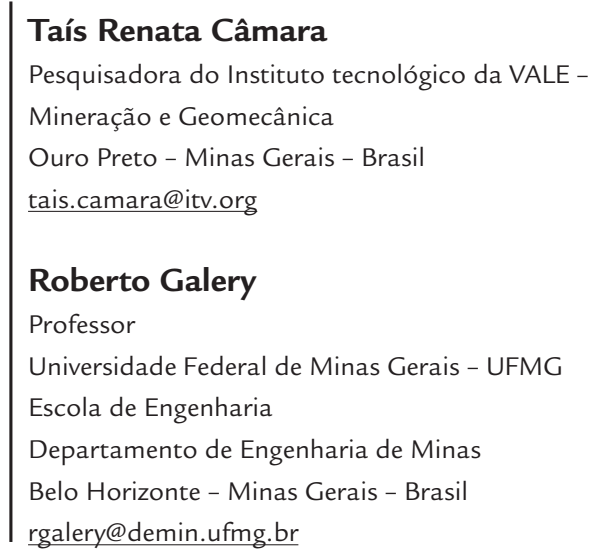

\section{Introduction}

Nested pits are the actual standard of mine scheduling, which was introduced by Lerchs and Grossmann (Lerchs and Grossmann, 1965). The methodology builds a parametric analysis of the reserve. Based on the progressive reduction of a commodity's price to obtain smaller pits, considered as sub multiples of the final pit (Lerchs and Grossmann, 1965). These pits represent an attempt to determine a scheduling process through mathematical formulations (Meagher and Dimitrakopoulus, 2014). This methodology presents two main limitations: the definition of the pushbacks through the nested pits

\section{Classical methodology}

The mine planning process is usually performed though a bottom-up strategy, whereby y the final pit limit is initially defined and later the nested pits. The goal of the first stage is to determine which blocks should be mined in order to maximize profit, while respecting operational constraints (Askari And Awuah, 2009). The technology is named bottom-up because the final pit limit is determined before the upper intermediate pits are built (Meagher and Dimitrakopoulus, 2014). The ultimate pit limits, are the combination of blocks that maximize the total discounted cash flow of the project and respect slope constraints (Almeida, 2013). The most common strategies adopted are: Lerchs and Grossmann (LG) algorithm (Lerchs

\section{Direct block scheduling}

A Direct Multi-Period Scheduling is an improvement of the classical methodology of Lerchs-Grossmann (Almeida, 2013). It is able to reflect the steps developed by a real mine operation, going through each time period's mining may present non-optimal solutions for the problem due to the price discount factor methodology used, and there is commonly a gap issue in the space solutions between consecutive pushbacks. The incorrect mass distribution is related to a price discount factor methodology to generate the push back. Johnson (1968) was the first to propose a formulation able to schedule blocks directly to define the pit limits. Due to computational limitations and difficulties in developing approximation methodologies to simplify the problem, this methodology attracted less attention from the academic community in comparison with the Lerchs-
Grossmann's proposition. In the last decades, several experts developed tactics to use this knowledge successfully (Almeida, 2013). In this study, tests were conducted in order to compare these methodologies focusing on the capacity to mine higher grade blocks early in mine life, which is referred to as voracity. The results point to considerable advantages of the Direct Block Scheduling methodology in terms of mine planning and economics, mainly due to the achievement of the desired NPV with the extraction of lower ore quantities being easier to reach the production targets with higher resultant present value. and Grossmann, 1965) and the floating cone algorithm (Pana, 1965).

After determining the final pit limit, it is necessary to build the push back using the discount factor (SME, 2011). The ultimate pit is the input of a process called parameterization, which economically discretizes the space defining series of nested pits that generates increasing pit-by-pit discounted cash flow (Whittle, 1999). The parameterization approach iteratively changes the economic value of the blocks using a revenue factor and determines the ultimate pit limit based on the modified block values (Askari and Awuah, 2009).

This parameterization results in a series of nested pits with different mate- rial quantity and quality. The user selects the "best" nested pit to be the final pit limit, but this was defined without the application of discount factors (Pana, 1965). The group of nested pits smaller than the selected one will be used to define the pushbacks. The incremental tonnage between two subsequent nested pits represents a pushback. The pits determined via the parameterization approach still have the value decreased by the application of discount rates. Regardless of the step-size of changing the block value, there is a possibility that there is no appropriate selection of pushback such that the material tonnage is uniformly distributed between the pushbacks (Askari and Awuah, 2009). limits until it reaches the final pit as a consequence of profitable periods. As was expected, the pit limits follow a top-down sequence, representing a real operation development (Johnson, 1968). This formulation represents an advance if compared to formulations commonly used to optimize mine production schedules. Direct Block Scheduling applies correct discount factors to cash flow over production years resulting in correct Present Value forecast assessments (Almeida, 2013). The efforts 
of R. Dimitrakopoulus and his colleagues along the last 20 years was one of the bases to join the methodology proposed by Johnson (1968) and the surface control techniques developed by Ramazan(2004) and Leite (2010).

This formulation considers each block present in the model as a single unit for each mine period, not only a group of units inside the final pit, as considered by the precedence theory (Almeida, 2013). The formulation is based on an objective function and constraints such as occurs in mixed integer programming (Dantzig and Thapa, 1997). Ramazan (2012) applied a data arrangement in order to minimize uncertainty limitations and turn feasible all possible scenarios, developing the mix integer program initially proposed by Dantzig (1955), in a way to consider all periods simultaneously. The optimization based on multi-periods applies heuristics and other approximating strategies to determine the best solution (Leite and Dimitrakopoulos, 2010). Therefore, the defined schedule for each period will improve accuracy and will take a longer time period to find the solution, due to the great computational effort required.
Multi-period optimization

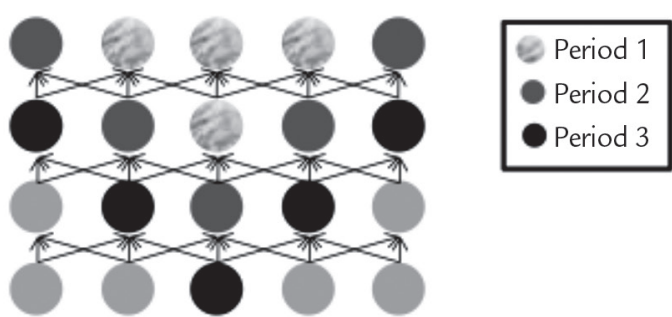

\section{a. Formulation of direct Multi-Period Scheduling}

Ramazan (2012) proposed a Scheduling able to maximize the Net general formulation for a Multi-Period Present Value (NPV) and control the ore

tonnage, grade, and target production.

$$
\begin{gathered}
\text { Max } \sum_{t=1}^{P}(\text { Part } 1-\text { Part2 }+ \text { Part3 - Part4) } \\
\text { Part1 }=\sum_{t=1}^{N} E\left\{N P V_{j}^{t}\right\} b_{i}^{t} \\
\qquad \text { Part2 }=\sum_{j=1}^{u} E\left\{N P V_{j}^{t}+M C_{j}^{t}\right\} w_{j}^{t} \\
\text { Part3 }=\sum_{s=1}^{M} E\left\{S V^{t} / M\right\} K_{s}^{t}
\end{gathered}
$$

Where: Block j at period t.

$M C_{j}^{t}=$ Mine cost of block $j$ at period $t$.

$\mathrm{W}_{\mathrm{j}}^{\mathrm{t}}=$ Percentage of block $\mathrm{j}$ sent to waste dump during period $\mathrm{t}$.

$\mathrm{SV}^{\mathrm{t}}=$ Profit per tonnage at period $\mathrm{t}$.

$M=$ Number of simulated models.

$\mathrm{b}_{j}^{\mathrm{t}}=$ Percentage of block mined on the same period.

$\mathrm{K}_{\mathrm{s}}^{\mathrm{t}}=$ Ore recovered on stock pile in the simulated model $\mathrm{s}$.
Part1 of the objective function accounts for the expected NPV obtained by mining the fractions $b_{i}^{t}$ of blocks $i$ over period $t$ and processing the blocks during the same period. Part2 compensates for the expected NPV loss from fractions $w_{j}^{t}$ of blocks $j$ mined over the same period $t$ but sent to the stockpile, with the respective cost $M C_{j}^{t}$. Part3 stands for the expected NPV obtained from the amounts of ore $K_{s}^{t}$ processed from the stockpile during period $t$, and $S V^{t}$ is the profit per ton generated. $P$ stands for the number of periods, $N$ is the total number of blocks, $u$ is the number of blocks considered for stockpiling; and $M$ the number of simulated models.
The penalties applied to the benefit function force the system to find a solution able to comply with the requirements, but if the desired solution cannot be reached, the nearest feasible solution is presented. DBS can consider each ore block individually because it maximizes the sum of the blocks. Lerchs-Grossmann formulation 
considers the sum of the node branches. The ability to add each block individually

\section{b. Simulated annealing}

Simulated Annealing is a heuristic algorithm to solve hard convergence problems. This algorithm supports the local search step and the global optimization based on metallurgical annealing concepts. This methodology begins the process on a generic solution followed

\section{c. Tabu search}

The Tabu Search is classified as a dynamic neighborhood methodology, updated according to the recent search history. This step is responsible for sup- facilitates the determination of the optimal solution, since the system is free to reach

by a neighborhood local search. The extension of the local search is based on temperature concepts; a high temperature means a high growth of function benefit value. Far from the optimal value, the temperature tends to increase in order to demonstrate which selection of a block

plying the Simulated Annealing, locating the feasible solutions on a restrict space. Each interaction provides a solution to be investigated by the optimization system. all mineable blocks, and is not limited to a local graph restriction (Almeida, 2013).

contributes to the increase of the benefit function. The temperature decreases if the solution reaches a constant value, indicating local convergence. Another run is executed to ensure the solution is not sustained by local attraction (Glover and Kochenberger, 2003).

The solution rejected by the system composes the Tabu priority, and the solution reproved in the recursive process is postponed to be tested again (Nogholi, 2015).

algorithm to select the most profitable blocks at the initial periods, resulting in an avid process if compared to the classical methodology. Higher grade zones will likely be mined as early as possible, increasing NPV.

A second effect of voracity is related to final pit limits. The blocks close the final limit of Lerchs-Grossmann (Lerchs and Grossmann, 1965) and will decrease profit due to the discount increase with time, when compared to a Multi-Period Scheduling, which may result in converting a feasible block to unfeasibility.

The voracity resultant from the correct application of discount factors may conduce a scheduling process able to promote a super extraction rate of higher grade zones of the deposit (Edmundo, 2014).

\section{e. Discount factor}

As it is impossible to mine the whole deposit at the same time, companies will be required to process ore fractions in the future, and this requires

the adjustment of the value of this ore, once it loses value over time. The value of this ore in the future is called present value, and it is estimated adjusted

$$
\text { Present Value }=\frac{X}{(1+r)^{t}}
$$

or to longer time periods. NPV is the sum of all Present Values of a project. Therefore, greater discounts penalize by applying a discount factor where $\mathrm{x}$ is the cost or outcome of interest, $r$ is the discount rate and $t$ represents the number of periods.

the NPV due to the decrease of Present Values (Edmundo, 2014).

model are presented in Table 1. In order to set the appropriate plant route, the material was classified into two groups according Table 2. to result in greater impact on present values when applied to elevated rates

\section{Real application study}

This study used data from an Iron deposit formed in the Pre-Cambrian period, and located within the "Quadrilatero Ferrífero" area of Minas Gerais, Brazil.
This formation is a typical example of the greenstone belt, formed by Meta volcanic rocks and Meta sediments (CPRM, 2014). The main characteristics of the block 
Table 1

Main characteristics of block model.

Table 2

Ore set.

This application compares the final pit obtained by optimization and scheduling of the deposit using the metrology based on Lerchs-Grossman's algorithm (Lerchs and Grossmann, 1965) and the nested pit (Whittle, 1999), referred to as classical methodology. The ore production target was set to 40 million tons per year. As previously discussed herein, optimization is supposed to reach the highest feasible grade in all

\begin{tabular}{c|c|c|c|c|c|c} 
Block N & East Dim. & North Dim. & Z Dim. & Volume $\mathrm{m}^{3}$ & $\mathrm{Fe}(\%)$ & $\mathrm{SiO}_{2}(\%)$ \\
\hline $3,019,104$ & 12.5 & 12.5 & 15.0 & $7,076,025,000$ & 41.10 & 32.32 \\
\hline
\end{tabular}

\begin{tabular}{c|c|c|c|c} 
Type & $\mathrm{Fe}(\%)$ & Concentrate Grade & Mass Recovery & Metallurgical Recovery \\
\hline Rich Ore & 38.69 & 64.00 & 52.00 & 86.02 \\
\hline Poor Ore & 59.29 & 64.00 & 83.38 & 90.00 \\
\hline
\end{tabular}

applications developed, in an attempt to maximize NPV.

These methodologies will be compared to determine how the DBS face the optimization problem. The final pit was optimized using Micromine software, based on Lerchs-Grossmann methodology. In order to test the Direct Block Scheduling, the Simsched software was used. The benefit function is identical in both software. The two applications developed are:

1. Lerchs-Grossmann, executed in Micromine;

2. Direct Block Scheduling, executed in Simsched.

To set technical and economic parameters used by systems, it is necessary to build the benefit function. The function is the sum of the costs and expenses to mine the block. The parameters used are presented in Table 3 and Table 4.

$$
\begin{gathered}
\text { Benefit Function = Block Value }- \text { Block Costs } \\
\text { Block Value }=\text { Recovered Material x Price } \\
\text { Block Cost }=\text { Mined Material } \times \text { Sum of Costs }
\end{gathered}
$$

Table 3 Optimization parameters.

\begin{tabular}{c|c} 
Parameter & Value \\
\hline Dilution & $0 \%$ \\
\hline Mine recovery & $100 \%$ \\
\hline Sales Price & $70 \cup S \$$ \\
\hline Mine Cost(Ore and Waste) & $3.19 \cup S \$ / t$ \\
\hline Administrative Cost & $0.63 \cup S \$ / t$ \\
\hline Process Cost & 5.85 US\$/t \\
\hline Sales Cost & 11.13 US\$/t (Product) \\
\hline Cut-Off Rich Ore & $52 \%$ \\
\hline Cut-Off Poor Ore & $30 \%$ \\
\hline Rich Ore Product & $100 \%$ Pelled \\
\hline Poor Ore Product & 40 Mt ROM / Year \\
\hline Production Target & $10 \%$ Year \\
\hline Discount Factor &
\end{tabular}

Table 4 Layout parameters.

\begin{tabular}{c|c|c}
\hline Parameter & Lerchs-Grossmann & DBS \\
\hline Vertical Advance & $40 \mathrm{~m}$ & $40 \mathrm{~m}$ \\
\hline Horizontal Advance & $70 \mathrm{~m}$ & $70 \mathrm{~m}$ \\
\hline Operational Base & $50 \mathrm{~m}$ & $50 \mathrm{~m}$ \\
\hline Pit Base & $50 \mathrm{~m}$ & $50 \mathrm{~m}$ \\
\hline Strip Ratio & None & None \\
\hline Grade Control & None & None \\
\hline Slope Angle & $40^{\circ}$ & $40^{\circ}$ \\
\hline
\end{tabular}


The main objective is to test the avidity of methodologies; some operational

\section{Results}

The focus of this study was to analyze the avidity of each methodology and compare. Figure 2 shows the results obtained in each scenario for total mass movement, using similar numerical accuracy for both methods. The system based on LerchsGrossmann methodology divides the blocks parameters possibly limit this avidity. Limited strip ratio and grade control can influ- ence the results because the objective is to remove high quantity of rich ore quickly.

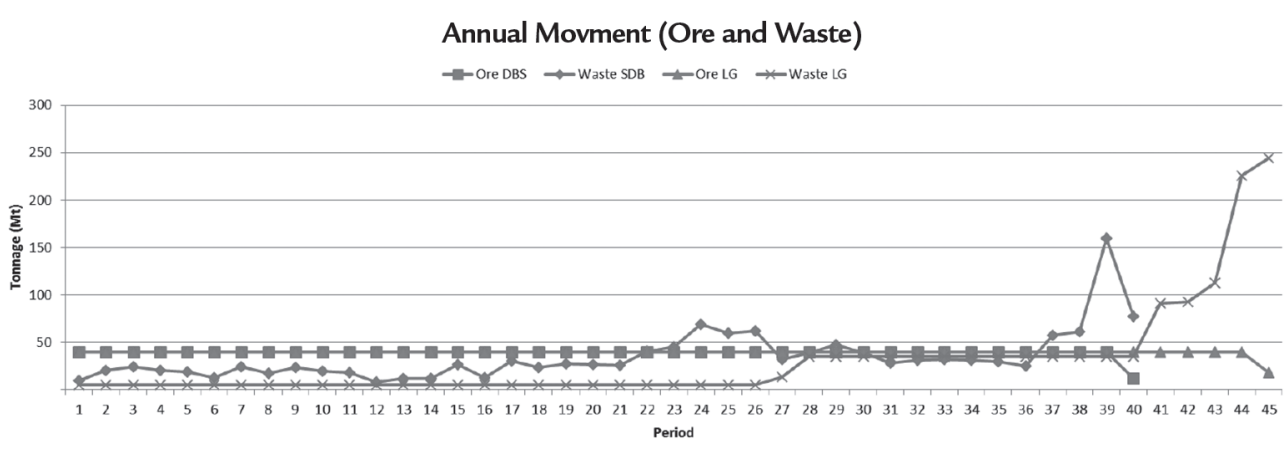

Figures 3, 4 and 5 confirms the higher voracity of the SDB methodology, reaching higher grades in the initial periods. The ability to select higher grade
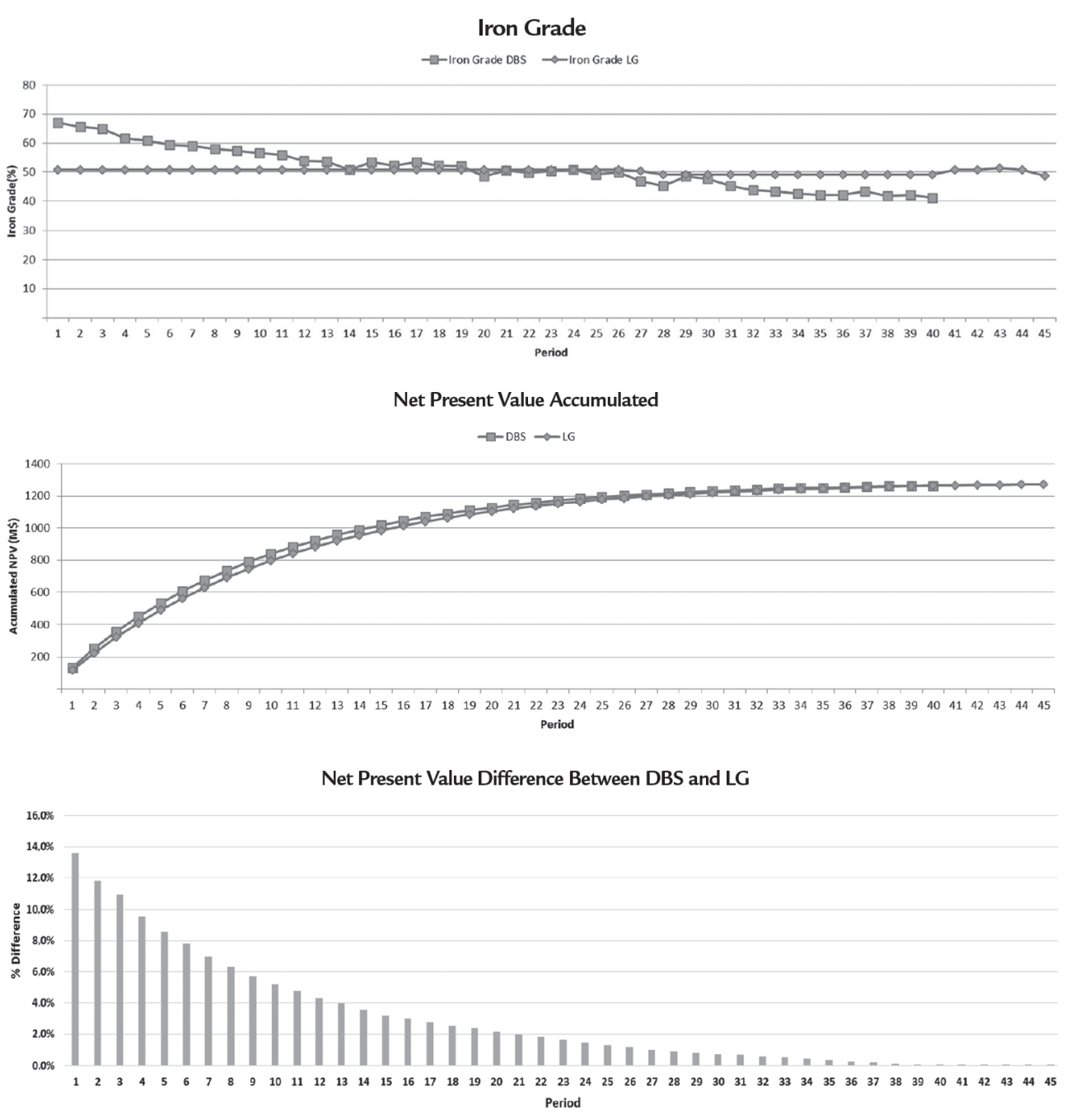

blocks in early periods is a result of combined factors, such as the application of Simulated Annealing, Tabu Search and correct discount factors. The grade

to reach the proposed ore production, but the DBS only considers extraction of the entire block at a period of time, and this reliability is increased due the SDB mining only entire blocks because this provides greater grade reliability compared to sub blocks. Due the ability of the Direct Block Scheduling to mine higher grade blocks first, it may anticipate the waste involved in accessing the greater block values. Analyzing both results, it is clear that both methodologies tend to postpone the waste removal, confirming the avidity of these methods.

Figure 2

Annual material

movement.(Source: Author).

obtained in the initial years is able to provide greater present value and compensate the waste tonnage mined in the initial period.

Figure 3

Iron grade. (Source: Author).

Figure 4

Accumulated NPV. (Source: Author)

Figure 5

Net Present Value

Percentage Difference. (Source: Author). 
An important consideration is the SDB ability to smooth the mass transitions between the periods. The peaks of material handled are avoided to aid the mining operation (Almeida, 2013). The voracity of the DBS methodology provides a huge difference for mine plan-

\section{Conclusion}

DBS has proved be a promising technology, due the ability to reach the same order of NPV generated by the Lerchs-Grossmann's methodology, using correct discount factors and considering integer blocks mined in each period. The NPV of DBS can achieve a similar value in a shorter time period compared to Lerchs-Grossmann. Direct Block Scheduling allows the application of adequate discount factors and reaches higher values in the early mining periods. The application of the adequate discount factor is more significant for limiting blocks, ning but with similar cumulative NPV: the DBS provides higher present values in the initial years when the expected mining life is 40 years; five years less than the expected mine life obtained through the classical methodology.

Last periods that are penalized with greater economic discounts, and there may occur block value decrease due discount factor value increase. Blocks located at the edges of LerchsGrossmann's final pit probably has not been mined using the Direct Block Scheduling methodology. possibly occurring value reduction of the present value and this may transform feasible mined blocks into unfeasible ones, lLeading to the reduction of available reserves. Therefore, there is a trend for classical methodology to overestimate reserves and underestimate ore grade.

Heuristic models based on Simulated Annealing are able to analyze each block separately, and Tabu search is able to find a group of solutions near of global optimum, due to mathematical formulations. These mechanisms are able to find a solution with higher present value in the initial periods, due to the ability of searching and discovering avid solutions or higher grade blocks. The application of the correct discount factor turns the difference between block values more evident because of the progressive decreasing value of blocks over time. This correct factor and the applied heuristics are responsible for scheduling the block to be mined in the most profitable period, conducing to the mentioned benefits and highlighting the voracity to mine the most profitable blocks, respecting the target restrictions.

\section{References}

ALMEIDA, A. M. Surface constrained stochastic life-of-mine production schedulling. Research Report 2013. Montreal, Quebec, Canada: Cosmo Lab - McGill University, 2013. v. I, p. 215 - 253.

ASKARI-NASAB, H., AWUAH-OFFEI, K. Open pit optimisation using discounted economic block values. Mining Technology, v. 118, p. 1 -13, 2009.

CPRM. GEOPARQUE QUADRILÁTERO FERRÍFERO (MG). Itabira, Brazil, CPRM Press, v. 1, p.183-220, 2014.

DANTZIG, G. B., THAPA, N. M. Linear programming. New York: Springer-Verlag Press, 1997.

EDMUNDO, T. Avaliação de empreendimentos e recursos minerais. Estimativa de Recursos Minerais. Curaumilla: Oficina de Textos Press, 2014. p. 101-137.

GLOVER, F., KOCHENBERGER, G. A. Handbook of Metaheuristics. New York, Boston, Dordrecht, London, Moscow: Kluwer Academic Publishers, 2003.

JOHNSON, B. T. Optimum open pit mine production scheduling. Berkley, California: University of California, 1968. (Master Thesis).

LEITE, A., DIMITRAKOPOULOS, R. Production scheduling under metal uncertainty - application of stochastic mathematical programming at an open pit copper mine. Mining Technology, The Australasian Institute of Mining and Metallurgy, v. 116, p. 109-118, 2010. (Spectrum Series).

LERCHS, H., GROSSMANN, L. F. Optimum design of open pit mines. Canadian Mining and Metallurgical Bulletin, Montreal, Canada, v. LXVIII, p.17-24, 1965.

MEAGHER, C., DIMITRAKOPOULUS, R. Optimized open pit mine design, pushbacks and the gap problem - a review. Journal Of Mining Science, v. 50, n. 3, p. 508-526, 2014.

NOGHOLI, A. Optimisation of open pit mine block sequencing. Brisbane, Queensland, Australia: Queensland University of Technology, 2015. (Doctor of Philosophy Research).

PANA, M. T. The simulation approach to open pit design. In: APCOM SYMPOSIUM. v. 5, p. 127-138, 1965.

RAMAZAN, S., DIMITRAKOPOULOS, R. Production scheduling with uncertain supply: a new solution to the open pit mining problem. Optimization and Engineering, v. 13, p. 1-20, 2012.

SME. SME mining engineering handbook. (3rd ed.). Society for Mining, Metallurgy and Exploration, 2011. p.325-342. 
WHITTLE, J. A decade of open pit mine planning and optimization - the craft of turning algorithms into packages. In: Th APCOM SYMPOSIUM, 28. 1999. p. 15-22.

Received: 10 October 2016 - Re-submitted: 21 August 2017 - Accepted: 19 September 2017. 